\title{
Self-efficacy and KM course weighting selection: can students optimise their grades?
}

\author{
Nick Bontis* \\ DeGroote School of Business, \\ McMaster University, \\ 1280 Main Street West, DSB No. 207, \\ Hamilton, Ontario, L8S 4M4, Canada \\ E-mail: nbontis@mcmaster.ca \\ ${ }^{*}$ Corresponding author
}

\section{Timothy Hardie and Alexander Serenko}

Faculty of Business Administration,

Lakehead University,

955 Oliver Road, Thunder Bay,

Ontario, P7B 5E1, Canada

E-mail: tim.hardie@lakeheadu.ca

E-mail: aserenko@lakeheadu.ca

\begin{abstract}
The purpose of this research study is to evaluate whether or not students who choose to alter the grade weightings of required assignments a priori, in accordance with self-precepts of efficacy, improve their final course performance. Data was collected across three sets of MBA students who completed a course on strategic knowledge management. Results show a slight increase in overall performance when students optimise their weightings a priori; additionally, students demonstrated an ability to optimise their weightings correctly for specific course components related to technology and participation.
\end{abstract}

Keywords: knowledge management; curriculum design; education; class participation.

Reference to this paper should be made as follows: Bontis, N., Hardie, T. and Serenko, A. (2008) 'Self-efficacy and KM course weighting selection: can students optimise their grades?', Int. J. Teaching and Case Studies, Vol. 1, No. 3, pp.189-199.

Biographical notes: Nick Bontis is an Associate Professor of Strategic Management at the DeGroote School of Business, McMaster University. $\mathrm{He}$ received his $\mathrm{PhD}$ from the Ivey Business School, University of Western Ontario. He has published extensively in a variety of academic journals and has completed three books. He is recognised as a Leading Professional Speaker and Consultant in the fields of intellectual capital, knowledge management and organisational learning. He launched Canada's first KM course in an MBA program in 2001 and has been awarded the business school's outstanding MBA Professor while teaching that course twice in 2004 and 2006. 
Timothy Hardie has been involved in International Education for the past ten years, teaching and designing curriculum for universities, private schools, training colleges, and corporate clients in China, Japan, Australia and Canada. $\mathrm{He}$ holds a BEdu and an MBA in International Business and is a Doctoral Candidate at Monash University, Australia. He is currently lecturing at Lakehead University in Thunder Bay, Ontario, Canada.

Alexander Serenko is an Assistant Professor of Management Information Systems in the Faculty of Business Administration, Lakehead University. He holds a MSc in Computer Science, an MBA in Electronic Business, and a PhD in Management Science/Systems. His research interests pertain to intelligent agents, user technology adoption, knowledge management, and innovation. His papers appeared in various refereed journals, and his papers received awards at Canadian and international conferences.

\section{Introduction}

"In their daily lives, people continuously make decisions about what courses of action to pursue and how long to continue those they have undertaken. Because acting on misjudgments of personal efficacy can produce adverse consequences, accurate appraisal of one's own capabilities has considerable functional value." (Bandura, 1982)

The concept of self-efficacy, defined by Bandura (1981) as a judgement about how well one can manage any particular course of action or complete a specific task has been taken up by a variety of management researchers in the field of academic assessment (Chamorro-Premuzic and Furnham, 2003a, 2003b; de Fruyt and Mervielde, 1996; Furnham and Chamorro-Premuzic, 2004; Furnham et al., 1998a, 1998b; Furnham and Medhurst, 1995; Matthews, 1999; Petrides et al., 2005). Traditional measures of academic success focus predominantly on written examinations (Chamorro-Premuzic et al., 2005), although many researchers are now exploring alternate measures of academic performance (Walker, 2003) and the subsequent impact on learning outcomes and retention. In this paper, we examine three cohorts of MBA students enrolled in a specific course to determine whether their ability to alter the grade weightings of required assignments in accordance with self-precepts of efficacy improved their performance.

Different students have differing abilities and various precepts of their own ability to undertake a specific task in a classroom. In this study, students enrolled in an MBA-level knowledge management course were given the opportunity to alter grade weightings to reflect personal measures of self-efficacy for a varied success measurement portfolio. This portfolio included written reports, a simulation exercise, a written exam and a participation grade.

\section{Literature review}

According to Linnenbruck and Pintrich (2003), students with a high sense of efficaciousness for academic measurement tasks are more likely to work hard, to persist and to seek assistance, if required. Research has demonstrated that strong efficacy beliefs result in a greater motivation and better retention of information (Wigfield, 1998; 
Zimmerman and Martinez-Pons, 1990), which enhances the overall learning process. Bontis et al. (2006) confirm that offering a variety of pedagogical techniques, particularly for the purposes of performance measurement, results in very little deterioration of learning value over time. Schunk (2003) further demonstrates that effective learning does not require an extremely high sense of efficacy, only that it be high enough to sustain interest in the task.

Bandura's construct of self-efficacy requires a domain in which to operate. Domains can operate on either an internal or external platform, or both, simultaneously. External platforms for efficacy beliefs in the classroom would include grades, awards, citations and other referents to maximal performance. Internal platforms would include concepts of personal bests, individual goal setting and other referents to typical performance (Chamorro-Premuzic et al., 2005). Beliefs about efficacy can operate on both platforms, as long as the two coincide. For example, students might hold highly efficacious beliefs about their ability to deliver a maximal performance and achieve the top grade (external platform), and high beliefs about their ability to perform better than the last performance measure indicated, and thus increase their typical performance (internal platform), as long as the last performance measure was sufficient to qualify for the top grade. Any measurement of performance improvement would have to account for the nature of the domain for the belief since improvements on an internal domain platform will not necessarily be reflected externally.

Efficacy judgements are based on four sources of information: enactive attainments, vicarious experience, verbal persuasion, and physiological state (Bandura, 1982). Efficacy judgements based on enactive experiences are, according to Bandura, the most authentic sources of efficacy because they are based on mastery experiences. Repeated success with academic performance measurement tends to result in increased precepts of efficacy for those performance measures. Students come to a classroom with years of experiences that may or may not have represented mastery experiences. Observing the performance of others and receiving verbal persuasion can also increase efficacy beliefs, and are fairly easily managed by classroom instructors by allowing ample opportunity for students to present findings and field inquiries from one another. Walker (2003) further refines Bandura's categories for cultivating classroom based efficacy beliefs surrounding literacy skills. Successful experiences cultivate efficacy since students believe their own efforts have resulted in success. To lesser, but still significant degrees, positive verbal responses, meta-cognitive strategies (e.g., asking questions and checking understanding against content) and social comparisons (e.g., grades, awards) can encourage beliefs about efficacy. Classroom instructors can enhance learning and retention by giving choices to students and allowing them to maximise their performance based on their own strengths. In this study, students were given choices to position the weights of course evaluation components that might potentially allow them to maximise their grade according to self-percepts of efficacy for particular types of performance measurement. As such, students were given opportunities within the course to develop efficacy beliefs through enactive attainments by five separate performance measures. These performance measures include vicarious experiences, through group and individual performance, and verbal persuasions through classroom participation. Importantly, students were able to manage physiological states by lowering the value of assignments that increase their visceral arousal levels and thus diminish performance. Taken together, students' efficacy beliefs, and their subsequent individual performances, should increase when measured against the individual performance of students who did not alter grade weightings to 
reflect their personal strengths. Specifically, we would expect students to show marked improvement in those tasks that offer predictability and controllability. Bandura (1982) demonstrates in his work that predictability reduces stress and increases the ability to cope with threatening situations, while controllability offers different techniques for managing those threats.

\section{Course description}

The P727 'Strategic Knowledge Management' course has been offered at the DeGroote School of Business, McMaster University since Fall 2001. In this second-year MBA elective course, students are exposed to various aspects of knowledge management that teach course graduates how to effectively manage individual, group, and organisational knowledge assets (Bontis, 2002a). Knowledge management is a burgeoning academic field of business administration that is growing exponentially (Serenko and Bontis, 2004). Much of the literature focuses on a firm's ability to harvest the full potential of its intellectual capital (O'Regan et al., 2001; Choo and Bontis, 2002; Seleim et al., 2004; O'Donnell et al., 2006). Practitioners, such as Chief Knowledge Officers (CKOs), are also interested in learning more about best practices (Bontis, 2002b), technology and policies related to accelerating knowledge transfer within the firm (Bontis, 2001a, 2001b; Chauhan and Bontis; 2004) while promoting organisational learning (Bontis et al., 2002).

There are a numerous frameworks that are used in the course to understand how knowledge assets are generated and distributed drawn from various management disciplines such as human resources (Bontis and Fitz-enz, 2002; Stovel and Bontis, 2002), information systems (Curado and Bontis, 2006), strategy (Bontis, 1999), accounting (Bontis, 2003), economics and finance (Bontis, 1998; Bontis et al., 1999; Brett and Bontis, 2004). The course utilises a variety of pedagogical techniques, including lectures, case studies, readings, guest speakers, videos, and a simulation game. For more detail on the description and impact of this course, refer to the recent paper by Bontis et al. (2006) who conducted a survey of course alumni. The P727 outline is available at http://www.bontis.com/p727.htm.

In terms of an evaluation method, a final grade is calculated based on the following components (see Table 1):

Table 1 Evaluation components

\begin{tabular}{lllc}
\hline No. & Component & Description & Default weight (\%) \\
\hline 1 & Assignment 1 & Human capital metrics (group) & 15 \\
2 & TangoNet & Simulation game (individual) & 20 \\
3 & Assignment 2 & KM technology summary (group) & 15 \\
4 & Participation & Participation during lectures/cases (individual) & 25 \\
5 & Presentation & KM technology presentation (individual) & 5 \\
6 & Final test & Final case exam (individual) & 20 \\
& & Total & 100 \\
\hline
\end{tabular}


Assignment 1 is done in a team of $3-5$ students. Each group is assigned an industry and provided with human capital metrics for this sector over the past several years. This data is based on information collected by the Saratoga Institute (see www.SaratogaInstitute. com). The group prepares a professional report that includes:

- a statistical analysis of the human capital metrics longitudinally (over time) and across industries (benchmarking)

- an overview of events in the specific industry which would explain the human capital results in the past and compare them to what the data would be at present

- explanations of results with the use of citations and references from primary and secondary sources.

TangoNet is a leading simulation tool in the field of KM (see www.tangonow.net). In this game, each student is assigned to a company that competes for human capital, as well as intellectual capital resources, and customers (Bontis and Girard, 2000). The goal is to recruit, train, motivate and retain the most talented employees, match their talent with the needs of clients, attract the most suitable and profitable customers, and ultimately compete to win the highest market share and earn the largest profits. Each company is evaluated based on both tangible and intangible assets. At the end of the game, a student's grade is converted directly from the total market value of his or her company.

For Assignment 2, each group selects a KM technology to assess and review. A report is generated which includes:

- a company overview and technical product description

- a thoughtful analysis of the major problems associated with implementation and ongoing use of this KM tool

- a justified opinion about the future of this product and a recommendation for its potential acquisition.

Class participation requires students to be cooperative in sharing their views in classroom during lecture and case discussions. Students are encouraged to challenge and debate the discussed material as well as their peers' views. All responses are recorded by an attending teaching assistant. Physical presence in the classroom does not count towards participation. Each student's participation is valued at the conclusion of each case discussion. Teaching assistants are trained to look for quality vs. quantity and these results are then triangulated and confirmed by the instructor.

The final case exam is administered to each individual student at the end of the course. During a five-hour, closed-book test, students are responsible for reading, analysing and developing a solution to a KM case study. This case is typically drawn from a major case clearinghouse (e.g., Harvard, Ivey, ECCH). Students will have not been exposed to this case at all prior to the exam. Students are required to type their case solution response on a computer, and are limited to 3,500 words in total.

In addition, each student must do an individual presentation on the KM technology investigated in Assignment 2.

Prior to the third class of the course, students have a choice to customise their personal weighting breakdown of components, except for component No. 5 (presentation) which is fixed at $5 \%$. All other components may be customised at an increment of $5 \%$ so 
that each component is weighted between $10 \%$ and $25 \%$. Those students who wished to customise their breakdown, completed and signed a form. Those who did not, assumed the default breakdown.

\section{Research questions}

Accurate a priori appraisal of one's own capabilities should, in principle, allow students to select course grade weightings that align with their optimal grade potential. The first research question addresses this issue.

Research Question 1: Do KM MBA students, who select a pre-determined course breakdown that more closely aligns with their optimal course grade breakdown, perform better? In other words, do students know their own strengths?

Educational literature suggests that students' performance is enhanced when students are given choices about how they will be evaluated (Linnenbruck and Pintrich, 2003). The act of making a choice in itself indicates a sense of efficacy to determine personal strengths. The theory of self-efficacy would predict that students who alter the course weightings should experience improved individual performances, resulting in a slight boost to the overall class average, and a corresponding boost to their own performance. It is customary for instructors to maintain a certain grade average (or at least keep final grades within a specific range). Any increase in this pre-established limit that results from grade breakdown manipulation rather than better students' performance may be negatively viewed by the administration. Furthermore, students should know whether grade breakdown customisation helps them obtain a higher grade. The second and third research questions are presented as follows:

Research Question 2: Is there any difference in the performance of KM MBA students between those who select their own customised course grade breakdown and those who accept the instructor's default breakdown?

Research Question 3: Does the customisation of grade breakdown affect final grades of the students? In other words, does customisation artificially inflate the class average?

\section{Methodology and results}

In order to answer the study's research questions, a quantitative analysis of course performance of 66 students was done. For this, student performance data for the years 2003 (15 students), 2004 (33 students), and 2005 (18 students) were grouped. The combination of three datasets was possible for the following reasons. First, the same course structure, evaluation components, and grade breakdown rules were used. Second, the course was delivered by the same instructor (Dr. Nick Bontis) in the same manner. Third, all marking was done by the same teaching assistant (Dr. Alexander Serenko) who consistently employed the same grading procedures. Fourth, final grades means were the same in all three years $(F(2,63)=1.912, p>0.15$, n.s. $)$. 
In terms of the first research question, the highest grade was identified for each student by optimising his or her grade component breakdown after all the results were known. In other words, the weights of all components were adjusted to maximise the student's grade. Given that students were not able to adjust the weight of their Presentation grade, this mark was excluded from the analysis. After that, the difference between the optimal grade and the actual grade was calculated for each individual. The sample was split into two sub-samples at the median grade of $76.33 \%$; one sub-sample represented students who received below-average grades, and another represented those who obtain above-average grades. A t-test was conducted on the difference between the optimal and actual grade, and no statistically significance difference between the sub-samples was found $(t(64)=1.046$, n.s.).

To further attest this finding, the sum of the absolute difference between the optimal and chosen weight for each evaluation component was obtained for each student, and its correlation with the actual grade was calculated (Spearman Correlation $=0.036$, n.s.). It is noted that non-parametric techniques were applied since weights did not follow a normal distribution and were positioned on an ordinal scale. This demonstrates that there is no relationship between the actual students' performance and their ability to select optimal grade breakdowns.

In addition to this finding, it is important to know whether some students, regardless of their final grade, were able to correctly predict their grade breakdown optimisation for each evaluation component. For this, Spearman Correlations between the assigned and optimal weight for each component were calculated (see Table 2). The results demonstrate that students were able to correctly predict their performance on assignment 2 (KM Technology Evaluation) and participation.

Table 2 Chosen and optimal weight correlations

\begin{tabular}{lccccc}
\hline Component & Assign 1 & TangoNet & Assign 2 & Participation & Case exam \\
\hline Correlation & 0.191 & 0.127 & 0.257 & 0.378 & 0.113 \\
Significance & n.s. & n.s. & $p=0.038$ & $p=0.002$ & n.s. \\
\hline
\end{tabular}

With respect to the second research question, final grades of those who selected their own weight breakdown and those who assumed the default were compared. Again, presentation grades were excluded. The results revealed that 52 students customised their grades and 14 did not. No statistically significant difference in the average grades between the groups was found $(t(64)=0.719$, n.s.) Overall, this demonstrates that accepting the instructor's grade breakdown is to some extent customising; in other words, some students' optimal weight allocation coincided with the suggested one, and no changes were required.

With regards to the third research question, a list of those individuals who customised their breakdowns was formed (i.e., those who accepted the default instructor's breakdown were excluded). For each student, a grade based on the default breakdown was calculated, and this grade was paired-compared to his or her actual final course grade. The results revealed that the actual average final grade was 1.12 points higher $(t(51)=3.697$, $p<0.001)$. Allowing students to customise their grades thus had a minor impact on the class average. 


\section{Discussion and conclusion}

The objective of this research paper was to determine whether an MBA students' ability to alter their grade weightings of required assignments in accordance with self-precepts of efficacy improved their performance. The results are mixed and interesting.

Generally, there seems to be only limited material benefit in terms of overall grades for students who choose to customise their own weightings. However, students do, in fact, have the capability of boosting the value of certain specific components for which they predict they will perform better. Specifically, results showed that students did benefit by selecting appropriate weights for the KM Technology Assignment and Participation.

Interestingly, these two components by themselves seem to align with distinct student strengths, and mirror Bandura's observations about the role of predictability and controllability in increasing beliefs about efficacy. Generally speaking, students are keenly aware of their technological aptitude by the time they take this course and thus have a foundation of experience to draw on when making a judgement on how well they would do on a technology-oriented assignment. In other words, students find a technology assignment to offer a high degree of predictability. However, this explanation is somewhat tenuous given that this is a group assignment and the grade is shared among three or more students.

Participation, however, seems to clearly represent an area in which students know their strengths a priori, and have a clear understanding of what techniques they have at their disposal to maximise their participation marks. The participation mark offers a high degree of controllability. As a component for evaluation, participation is quite common in MBA curricula. Students will have had significant experience with participation in a variety of courses prior to taking P727. In fact, some students may have also had experience with participation in undergraduate programs (i.e., courses in humanities, commerce, and social sciences). Furthermore, participation is closely associated with the extroversion of a student (Lounsbury and DeNeui, 1996). Since most students are fully aware of the degree of their own personal extroversion, it is expected then, that students will also have an accurate sense of their own potential for class participation. To the extent that students can make an accurate self-assessment of their potential performance for this component, they can actually boost their grade.

Although the empirical justification for customised component breakdowns seems to be mixed, there is an alternate and indirect benefit. Students who walk into the classroom on the first day of classes generally view the course outline with a certain level of anxiety. Many of them direct their attention to the course evaluation components almost immediately. An alternative benefit for customised weightings may in fact be that it reduces student anxiety by offering them a sense of control of their own performance. Although, the results of this study show that this control is only slight, it may make a significant difference in terms of the confidence level of students who are just beginning a course in a field that is relatively new and unknown in academic circles. Giving students both the opportunity and the responsibility for determining how they are going to meet course requirements gives them power (Lengnick-Hall and Sanders, 1997). A major advantage of participatory design in performance evaluation is that it increases the individual's acceptance of the goal and commitment to attaining it (Lawler and Hackman, 1969). Bandura (1982) reminds us that since people are influenced more 
by how they read their performance successes than by the success per se, perceived self-efficacy [is] a better predictor of subsequent behaviour than performance attainment.

There are a few limitations to this research study. First, the course itself focuses on a domain of management literature that is relatively new and as such may in fact skew customised weightings for students compared to a more traditional course in which the content area is more widely accepted and known. Second, students within the MBA program at McMaster University are not accustomed to selecting customised weightings for their courses. If this research was conducted at a school in which this practice was more widely used, the results due to increased experience may have differed. Third, students were required to submit customised weightings for this course by the third class. Had that milestone been any earlier (or later), the results may have also differed.

However, there is an ample opportunity to take this research program further. For example, researchers could examine students' level of risk adversity between genders. Extant literature states that females are more reluctant to participate in class discussions, less willing to speak out and question teachers, and less likely to feel that they could hold their own in discussions with males peers (Carpenter et al., 1993). Based on these observations, it could be hypothesised that females would choose larger weights for components that require fewer interactions with peers, and rely more on a grading scheme with a greater emphasis on individualistic components. Another potential extension of this research would be to test age and education experience levels as a predictor of optimal weightings with the assumption that older and more experienced students would have a better sense of their strengths. Cultural factors that influence perceptions of self-efficacy can also impact performance in a variety of ways (Betz and Gwilliam, 2002; Creed et al., 2002; Gainor and Lent, 1998).

Notwithstanding the results of this particular study, more tests need to be completed in various contexts (e.g., undergraduate vs. graduate courses, arts vs. science courses) and in various international settings before a definitive and generalisable claim can be made regarding the effectiveness of student optimisation efforts. Although the practice of customised weightings is still uncommon, future students may desire the opportunity to control their own academic destiny.

\section{References}

Bandura, A. (1981) 'The self and mechanisms of agency', in Suls, J. (Ed.): Psychological Perspectives on the Self, Erlbaum, Hillsdale, New Jersey.

Bandura, A. (1982) 'Self-efficacy mechanism in human agency', American Psychologist, Vol. 37, pp.122-147.

Betz, N.E. and Gwilliam, L.R. (2002) 'The utility of measures of self-efficacy for the Holland themes in African American and European American college students', Journal of Career Assessment, Vol. 10, pp.283-300.

Bontis, N. and Fitz-enz, J. (2002) 'Intellectual capital ROI: a causal map of human capital antecedents and consequents', Journal of Intellectual Capital, Vol. 3, No. 3, pp.223-247.

Bontis, N. (1998) 'Intellectual capital: an exploratory study that develops measures and models', Management Decision, Vol. 36, No. 2, pp.63-76.

Bontis, N. (1999) 'Managing organizational knowledge by diagnosing intellectual capital: framing and advancing the state of the field', International Journal of Technology Management, Vol. 18, Nos. 5-8, pp.433-462. 
Bontis, N. (2001a) 'CKO wanted - evangelical skills necessary: a review of the Chief Knowledge Officer position', Knowledge and Process Management, Vol. 8, No. 1, pp.29-38.

Bontis, N. (2001b) 'Assessing knowledge assets: a review of the models used to measure intellectual capital', International Journal of Management Reviews, Vol. 3, No. 1, pp.41-60.

Bontis, N. (2002a) World Congress of Intellectual Capital Readings, Elsevier Butterworth Heinemann KMCI Press, Boston.

Bontis, N. (2002b) 'The rising star of the Chief Knowledge Officer', Ivey Business Journal (formerly Business Quarterly), Vol. 66, No. 4, pp.20-25.

Bontis, N. and Girard, J. (2000) 'Teaching knowledge management and intellectual capital lessons: an empirical examination of the TANGO simulation', International Journal of Technology Management, Vol. 20, Nos. 5-8, pp.545-555.

Bontis, N., Crossan, M. and Hulland, J. (2002) 'Managing an organizational learning system by aligning stocks and flows', Journal of Management Studies, Vol. 39, No. 4, pp.437-469.

Bontis, N., Dragonetti, N., Jacobsen, K. and Roos, G. (1999) 'The knowledge toolbox: a review of the tools available to measure and manage intangible resources', European Management Journal, Vol. 17, No. 4, pp.391-402.

Bontis, N., Serenko, A. and Biktimirov, E. (2006) 'MBA knowledge management course: is there an impact after graduation?', International Journal of Knowledge and Learning, Vol. 2, Nos. 3-4, pp.216-237.

Brett, D. and Bontis, N. (2004) 'Selling expertise to the highest bidder', KM Review, Vol. 7, No. 3, pp.28-31.

Carpenter, V., Friar, S. and Lipe, M. (1993) 'Evidence on accounting students: race, gender and expectations', Issues in Accounting Education, Vol. 8, No. 1, pp.1-17.

Chamorro-Premuzic, T. and Furnham, A. (2003a) 'Personality predicts academic performance: evidence from two longitudinal university samples', Journal of Research in Personality, Vol. 37, pp.319-338.

Chamorro-Premuzic, T. and Furnham, A. (2003b) 'Personality traits and academic exam performance', European Journal of Personality, Vol. 17, pp.237-250.

Chamorro-Premuzic, T., Furnham, A., Dissou, G. and Heaven, P. (2005) 'Personality and preference for academic assessment: a study with Australian University students', Learning and Individual Differences, Vol. 15, pp.247-256.

Chauhan, N. and Bontis, N. (2004) 'Organizational learning via groupware: a path to discovery or disaster?', International Journal of Technology Management, Vol. 27, Nos. 6-7, pp.591-610.

Choo, C.W. and Bontis, N. (2002) The Strategic Management of Intellectual Capital and Organizational Knowledge, Oxford University Press, New York.

Creed, P.A., Patton, W. and Watson, M.B. (2002) 'Cross-cultural equivalence of the career decision-making self-efficacy scale-short form: an Australian and South African comparison', Journal of Career Assessment, Vol. 10, pp.327-342.

Curado, C. and Bontis, N. (2006) 'The knowledge based-view of the firm and its theoretical precursor', International Journal of Learning and Intellectual Capital, Vol. 3, No. 4, pp.367-381.

de Fruyt, F. and Mervielde, I. (1996) 'Personality and interests as predictors of streaming and achievement', European Journal of Personality, Vol. 10, pp.405-425.

Furnham, A. and Chamorro-Premuzic, T. (2004) 'Estimating one's own personality and intelligence scores', British Journal of Psychology, Vol. 95, pp.149-160.

Furnham, A. and Medhurst, S. (1995) 'Personality correlates of academic seminar behaviour: a study of four instruments', Personality and Individual Differences, Vol. 19, pp.197-208.

Furnham, A., Forde, L. and Cotter, T. (1998a) 'Personality and intelligence', Personality and Individual Differences, Vol. 24, pp.187-192.

Furnham, A., Forde, L. and Cotter, T. (1998b) 'Personality scores and test taking style', Personality and Individual Differences, Vol. 24, pp.19-23. 
Gainor, K.A. and Lent, R.W. (1998) 'Social cognitive expectations and racial identity attitudes in predicting the math choice intentions of Black college students', Journal of Counselling Psychology, Vol. 45, pp.403-413.

Lawler, E.E. and Hackman, J.R. (1969) 'The impact of employee participation in the development of pay incentive plans: a field experiment', Journal of Applied Psychology, Vol. 53, pp.467-471.

Lengnick-Hall, C.A. and Sanders, M.M. (1997) 'Designing effective learning systems for management education: student roles, requisite variety, and practicing what we teach', Academy of Management Journal, Vol. 40, No. 6, pp.1334-1368.

Linnenbruck, E.A. and Pintrich, P.R. (2003) 'The role of self-efficacy beliefs in student engagement and learning in the classroom', Reading and Writing Quarterly, Vol. 19, pp.119-137.

Lounsbury, J.W. and DeNeui, D. (1996) 'Collegiate psychological sense of community in relation to size of college/university and extroversion', Journal of Community Psychology, Vol. 24, No. 4, pp.381-394.

Matthews, G. (1999) 'Personality and skill: a cognitive-adaptive framework', in Ackerman, P.L., Kyllonen, P.C. and Roberts, R.D. (Eds.): Learning and individual Differences: Process, Trait, and Content Determinants, Georgia Institute of Technology, Atlanta, pp.437-462.

O’Donnell, D., Tracey, M., Henriksen, L.B., Bontis, N., Cleary, P., Kennedy, T. and O'Regan, P. (2006) 'On the 'essential condition' of intellectual capital-labour', Journal of Intellectual Capital, Vol. 7, No. 1, pp.111-128.

O'Regan, P., O’Donnel, D., Kennedy, T., Bontis, N. and Cleary, P. (2001) 'Perceptions of intellectual capital: Irish evidence', Journal of Human Resource Costing and Accounting, Vol. 6, No. 2, pp.29-38.

Petrides, K.V., Chamorro-Premuzic, T., Frederickson, N. and Furnham, A. (2005) 'Accounting for individual differences in scholastic behavior and achievement', British Journal of Educational Psychology, Vol. 75, pp.239-255.

Schunk, D.H. (2003) 'Self-efficacy for reading and writing: influence of modeling, goal setting, and self-evaluation', Reading and Writing Quarterly, Vol. 19, pp.159-172.

Seleim, A., Ashour, A. and Bontis, N. (2004) 'Intellectual capital in Egyptian software firms', The Learning Organization: An International Journal, Vol. 11, Nos. 4-5, pp.332-346.

Serenko, A. and Bontis, N. (2004) 'Meta-review of knowledge management and intellectual capital literature: citation impact and research productivity rankings', Knowledge and Process Management, Vol. 11, No. 3, pp.185-198.

Stovel, M. and Bontis, N. (2002) 'Voluntary turnover: knowledge management friend or foe', Journal of Intellectual Capital, Vol. 3, No. 3, pp.303-322.

Walker, B.J. (2003) 'The cultivation of student self-efficacy in reading and writing', Reading and Writing Quarterly, Vol. 19, pp.173-187.

Wigfield, A. (1998) 'Children's motivations for reading and reading engagement', in Guthrie, J.T. and Wigfield, A. (Eds.): Reading Engagement: Motivating Readers through Integrated Instruction, International Reading Association, Newark, Delaware, pp.14-33.

Zimmerman, B.J. and Martinez-Pons, M. (1990) 'Student differences in self-regulated learning: relating grade, sex, and giftedness to self-efficacy and strategy use', Journal of Educational Psychology, Vol. 82, pp.51-59. 